\title{
PARTICLE SIZE ANALYSIS OF DIGESTED SLUDGE
}

\author{
JENNIFER I. HOUGHTON and TOM STEPHENSON*
}

School of Water Sciences, Cranfield University, Cranfield, Bedfordshire, U.K. MK43 0AL.

*Author to whom all correspondence should be addressed.

Tel: +44 (0) 1234750111 ext. 4054

Fax: +44 (0) 1234751671

e-mail: t.stephenson@cranfield.ac.uk

Short title for page headings: Particle size analysis of digested sludge

\begin{abstract}
Particle size analysis was carried out on six samples of digested sludge using laser diffraction. The digested sludge was produced in laboratory scale reactors under different feed regimes based on a mixture of primary and waste activated sludge. Laser diffraction proved capable of providing rapid, reproducible results of the particle size distribution of each sample, and highlighted differences between the different treatments. An increase in the level of waste activated sludge in the digester feed sludge led to a shift in the size distribution, with a decrease in the number of smaller sized particles.
\end{abstract}

Key words — particle size analysis; anaerobic digestion; sludge; laser diffraction 


\section{INTRODUCTION}

Anaerobic digestion is widely used in the UK as a method of sludge stabilisation, with $>50 \%$ of all wastewater sludge produced treated in this way (Davis, 1996). Changes that occur during the digestion process influence the fundamental characteristics of the sludge, e. g. the particle size (Lawler et al., 1986) and solids organic content (Parkin and Owen, 1986), which in turn influences properties such as the sludge dewaterability (Karr and Keinath, 1978; Lawler et al., 1986; Olb ter and Vogelpohl, 1993).

Particle size analysis has a long history (Heywood, 1970) but it was the development of electronic counting instruments, initially the Coulter Counter in the late 1940’s, that enabled the rapid sizing of individual particles (Lines, 1992). Technology has since advanced with methods such as laser diffraction (e.g. Olb ter and Vogelpohl, 1993) and ultrasound (Riebel, 1992) being applied. The application of electronic measuring devices to the particle size analysis of digested sludge has been limited to date, and focused mainly on the use of the Coulter Counter or similar instrument (Faisst, 1980; Lawler et al., 1986).

Faisst (1980) used the Coulter Counter with 6 variations of aperture and instrument settings to obtain the particle size distribution of 2 digested sludges over the range of approximately 1-60 $\mu \mathrm{m}$; the majority of the particles present having diameters of $<5 \mu \mathrm{m}$. Similarly, Lawler et al. (1986) used an electrozone type instrument to measure the particle size distribution of a number of laboratory derived digested sludges. The size range in this case was approximately $0.66-125 \mu \mathrm{m}$, with distribution peaks between 40 $50 \mu \mathrm{m}$ depending on the digester feed sludge. 
In order to measure the particle size using electrozone sensing, the sample must be dissolved in an electrolytic solution. This may affect the size of the sludge particles within the sample, as flocculation has been shown to be dependent on the interaction of multivalent cations with the microbial extracellular polymer network (Urbain et al., 1993). This problem is overcome if laser diffraction is used for particle size measurement, as the sample can be diluted in a solvent such as tap water. Laser diffraction is finding increasing popularity as a method of particle size analysis for wastewater samples (Friedrich et al., 1993; Olb ter and Vogelpohl, 1993; Neis and Tiehm, 1997; Biggs and Lant, 2000) but its application to digested sludge has been limited to date (Feitz et al., 2000).

The aim of this paper was to assess the feasibility of using laser diffraction in the form of the Malvern Mastersizer $2000^{\circledR}$ (Malvern Instruments Limited, Malvern, UK) to measure the particle size distribution of digested sludge. Six digested sludge samples were prepared, under controlled laboratory conditions, using different combinations of primary and waste activated sludge as the digester feed.

\section{MATERIALS AND METHODS}

Six laboratory scale anaerobic digesters were constructed from 5 l Quickfit ${ }^{\circledR}$ fermentation vessels as detailed previously (Houghton et al., 2000). Settled primary and waste activated (WAS) feed sludge was collected from Cambridge municipal wastewater treatment works (Anglian Water plc.). After collection, the feed sludge was divided into 0.5 and $1 \mathrm{l}$ aliquots, blended (Phillips Type: HR2845/AM) for $1 \mathrm{~min}$, and then frozen at 
$-20{ }^{\circ} \mathrm{C}$ until required. Before use, the sludge was defrosted for $24 \mathrm{~h}$ at room temperature, combined to produce the required feed composition (100\% primary (100\%); $80 \%$ primary:20\% WAS by volume (80\%:20\%); 60\% primary:40\% WAS by volume (60\%:40\%)), and warmed to $\sim 35^{\circ} \mathrm{C}$ in a waterbath before addition to the digesters. Seed sludge for the digesters was obtained from Milton Keynes municipal wastewater treatment works (Anglian Water plc.).

The digesters were run at $35^{\circ} \mathrm{C}$ and a hydraulic retention time (HRT) of $20 \mathrm{~d}$, with sludge being wasted/fed once per day. Digester performance was monitored on a daily (pH; temperature) and weekly (total solids (TS); volatile solids (VS); gas production) basis. All analysis was carried out as detailed in standard methods (APHA, 1992). The digesters were operated for 4 full HRT before a sludge sample was removed from each digester for particle size analysis.

Particle size analysis was carried out using the Malvern Mastersizer $2000^{\circledR}$, (stirrer speed $=350$; pump speed $=500$; ultrasonic $=$ off $)$ at Malvern Instruments Ltd., Malvern, U.K.. For analysis, each sample was diluted approximately 500-fold in tap water from Cranfield, before being analysed 10 times. These results were then averaged to produce the particle size distribution. The results were recorded as the particle volume percent in 70 discrete size ranges between 0.45 and $2000 \mu \mathrm{m}$.

\section{RESULTS AND DISCUSSION}

Sludge characteristics for both the feed and seed sludge are shown in Table 1. Each of the laboratory scale digesters operated satisfactorily throughout the $80 \mathrm{~d}$ 
operation period, with high levels of volatile solids reduction (VSR) (Table 2). Each of the different treatments operated in a similar manner, with differences between each of the matched pairs. At all times the $\mathrm{pH}$ remained $>\mathrm{pH} 7.0$ in each digester and the mean temperature ranged from $34.9-35.1^{\circ} \mathrm{C}$, indicative of normal mesophilic operation (Parkin and Owen, 1986) . As the concentration of WAS in the digester feed increased, there was a reduction in the TS, VS and VSR of the respective digesters (Table 2).

The particle size distribution of each digester sludge is illustrated in Figure 1, which shows the percentage of particles, by volume, between $0.45-2000 \mu \mathrm{m}$. No particles $<0.45 \mu \mathrm{m}$ were detected in any of the samples. A different size distribution was obtained for each of the treatment types, with good reproducibility between the matched pairs.

The digesters that were fed on $100 \%$ primary sludge showed one main peak in the size range 22-32 $\mu \mathrm{m}$. As the level of WAS in the digester feed increased, there was a shift in the particle size distribution towards larger particles with the peak at 22-32 $\mu \mathrm{m}$ becoming less pronounced, as a new peak developed at $110-140 \mu \mathrm{m}$. This is likely to be due to the differences in biodegradability of the different types of feed sludge and the method of storage. All of the primary and WAS was stored at $-18^{\circ} \mathrm{C}$ prior to use. As reported previously by Knocke and Trahern, (1989) indirect freezing changes the structure of the sludge particles, causing the formation of large, dense particles. This was most noticeable in the WAS samples. Larger particles, more resistant to degradation are therefore likely to be the cause of the shift in the particle size distribution as the level of WAS in the digester feed increased. Comparison of particle size data obtained by different methods is difficult, as the mean particle diameter is derived in different ways. 
Using electrozone sensing, Lawler et al. (1986) reported a distribution peak for digested sludge of approximately $40-50 \mu \mathrm{m}$, depending on the digester feed sludge. This is inbetween the 2 distribution peak values obtained here.

The $d(0.1), d(0.5)$ and $d(0.9)$ values indicate that $10 \%, 50 \%$ and $90 \%$ of the particles measured were less than or equal to the size stated. Where $100 \%$ primary sludge was used as the digester feed, the digested sludge had the lowest $d(0.1)$ and $d(0.5)$ values and the highest $d(0.9)$ value, reflecting the one single main peak in the 22-32 $\mu \mathrm{m}$ size range (Table 3). Increasing the proportion of WAS in the digester feed sludge caused an increase in the $d(0.1)$ and $d(0.5)$, whilst the $d(0.9)$ tended to decrease. Ten consecutive measurements were made of each sample, and the results averaged to produce the overall size distribution. Throughout the ten measurements the $d(0.1), d(0.5)$ and $d(0.9)$ remained stable, indicating that the shear exerted by the instrument during the measurement process was not causing floc breakage.

The sludge specific surface area was derived from the particle size distribution. Whilst not a wholly accurate value in that the assumption is made that all of the particles measured are spherical in diameter, the specific surface area data quoted in Table 3 clearly illustrates that the smaller particles contributed more in terms of specific surface area than the larger size fractions. The values obtained for the specific surface area of the sludge are less than those recorded by Lawler et al. (1986), and this is again likely to be due to the different method of measurement. 


\section{CONCLUSION}

The results presented above indicate that laser diffraction using the Malvern Mastersizer $2000^{\circledR}$ is capable of providing rapid, reproducible results of the particle size distribution of digested sludge, with no adverse shear effect on the floc structure. Particle size analysis clearly illustrated the differences between the different feed regimes used for the laboratory digesters. An increase in the level of waste activated sludge in the digester feed sludge led to a shift in the size distribution, with a decrease in the number of smaller sized particles.

\section{ACKNOWLEDGEMENTS}

JIH is funded by a UK Engineering and Physical Sciences Research Council (EPSRC) Grant GR/L 87255 and supported by Anglian Water plc. The authors thank Tina Rowney of Malvern Instruments Limited, UK, for assistance in the particle size analysis of the sludge samples.

\section{REFERENCES}

APHA (2000) Standard Methods for the Examination of Water and Waste Water, $18^{\text {th }}$ ed. American Public Health Association/Water Environment Federation, Washington DC, USA.

Biggs C. A. and Lant P. A. (2000) Activated sludge flocculation: on-line determination of floc size and the effect of shear. Wat. Res., 34(9), 2542-2550. 
Davis R. D. (1996) The impact of EU and UK environmental pressures on the future of sludge treatment and disposal. J. Chart. Inst. Wat. Environ. Manage. 10, 65-69.

Faisst W. K. (1980) Characterization of particles in digested sewage sludge. In: Particulates in water. Characterization, fate, effects, and removal. Eds. M. C. Kavanaugh and J. O. Leckie, Advances in Chemistry Series 189, pp. 259-282, American Chemical Society, Washington DC, USA.

Feitz A. J., Guan J. and Waite T. D. (2000) Size and structure effects on centrifugal dewatering of digested sewage sludge. Proceedings of $1^{\text {st }}$ World Congress of the International Water Association, Paris, France, $3^{\text {rd }}-7^{\text {th }}$ July 2000. Book 4, pp 203-210.

Friedrich E., Friedrich H., Heinze W., Jobst K., Richter H.-J., and Hermel W. (1993) Progress in characterization of sludge particles. Wat. Sci. Tech., 28(1), 145-148.

Heywood H. (1970) The origins and development of particle size analysis. In: Particle Size Analysis. Eds. M. J. Groves and J. L. Wyatt-Sargent, pp. 1-18. The Society of Analytical Chemistry, London.

Houghton J. I., Stephenson T. and Quarmby J. (2000) The impact of digester retention time on microbial extracellular polymer production and sludge dewaterability. Environmental Technology, (in press).

Karr P. R. and Keinath T. M. (1978) Influence of particle size on sludge dewaterability. J. Wat. Pollut. Control Fed., 50, 1911-1930.

Knocke W. R. and Trahern P. (1989) Freeze-thaw conditioning of chemical and biological sludges. Wat. Res., 23(1), 35-42.

Lawler D. F., Chung Y. J., Hwang S.-J., and Hull B. A. (1986) Anaerobic digestion: Effects on particle size and dewaterability. Journal WPCF, 58(12), 1107-1117. 
Lines R. W. (1992) The electrical sensing zone method (the Coulter principle). In: Particle Size Analysis. Eds. N. G. Stanley-Wood and R. W. Lines, pp. 350-373. The Royal Society of Chemistry, Cambridge, UK.

Neis U. and Tiehm A. (1997) Particle size analysis in primary and secondary waste water effluents. Wat. Sci. Tech., 36(4), 151-158.

Olb ter L. and Vogelpohl A. (1993) Influence of particle size distribution on the dewatering of organic sludges. Wat. Sci. Tech., 28(1), 149-157.

Parkin G. F. and Owen W. F. (1986) Fundamentals of anaerobic digestion of wastewater sludges. J. Eniron. Eng. (ASCE), 112(EE5), 867-920.

Riebel U. (1992) Ultrasonic spectrometry: On-line particle size analysis at extremely high particle concentrations. In: Particle Size Analysis. Eds. N. G. Stanley-Wood and R. W. Lines, pp. 488-497. The Royal Society of Chemistry, Cambridge, UK.

Urbain V., Block J. C. and Manem J. (1993) Bioflocculation in activated sludge: an analytic approach. Wat. Res., 27(5), 829-838. 
Table 1. Sludge characteristics: digester feed and seed sludge

\begin{tabular}{|l|c|c|c|}
\hline Sludge & TS $\left(\mathrm{g} \mathrm{l}^{-1}\right)$ & ${\mathrm{VS}\left(\mathrm{g} \mathrm{l}^{-1}\right)}$ & $\mathrm{COD}\left(\mathrm{mg} \mathrm{l}^{-1}\right)$ \\
\hline Primary feed & 68.5 & 57.6 & 118,000 \\
\hline WAS feed & 22.6 & 18.6 & 27,500 \\
\hline Digester seed & 28.6 & 16.8 & 29,600 \\
\hline
\end{tabular}


Table 2. Digester performance: TS, VS, VSR and gas production of each digester.

\begin{tabular}{|l|c|c|c|c|c|c|c|c|}
\hline $\begin{array}{l}\text { Digester } \\
\left(1^{\circ}: \text { WAS }\right)^{2}\end{array}$ & \multicolumn{2}{|c|}{ TS $\left(\mathrm{g} \mathrm{l}^{-1}\right)$} & \multicolumn{2}{c|}{ VS $\left(\mathrm{g} \mathrm{l}^{-1}\right)$} & \multicolumn{2}{c|}{ VSR (\%) } & \multicolumn{2}{c|}{$\begin{array}{l}\text { Gas production } \\
\left(\mathrm{ml} \mathrm{g}^{-1} \mathrm{VSR} \mathrm{d}^{-1}\right)\end{array}$} \\
\hline & mean & range & mean & range & mean & range & mean & Range \\
\hline $100 \%$ & 29 & $25-31$ & 19 & $15-22$ & 66 & $59-71$ & 255 & $205-297$ \\
\hline $100 \%$ & 28 & $26-31$ & 18 & $15-21$ & 67 & $61-73$ & 243 & $170-293$ \\
\hline $80 \%: 20 \%$ & 26 & $19-30$ & 17 & $13-19$ & 64 & $56-73$ & 243 & $212-304$ \\
\hline $80 \%: 20 \%$ & 26 & $24-29$ & 17 & $13-19$ & 64 & $57-69$ & 271 & $240-331$ \\
\hline $60 \%: 40 \%$ & 25 & $24-29$ & 16 & $14-18$ & 61 & $52-67$ & 237 & $197-288$ \\
\hline $60 \%: 40 \%$ & 25 & $23-29$ & 16 & $14-18$ & 61 & $53-68$ & 265 & $185-449$ \\
\hline
\end{tabular}

*primary to waste activated sludge ratio 


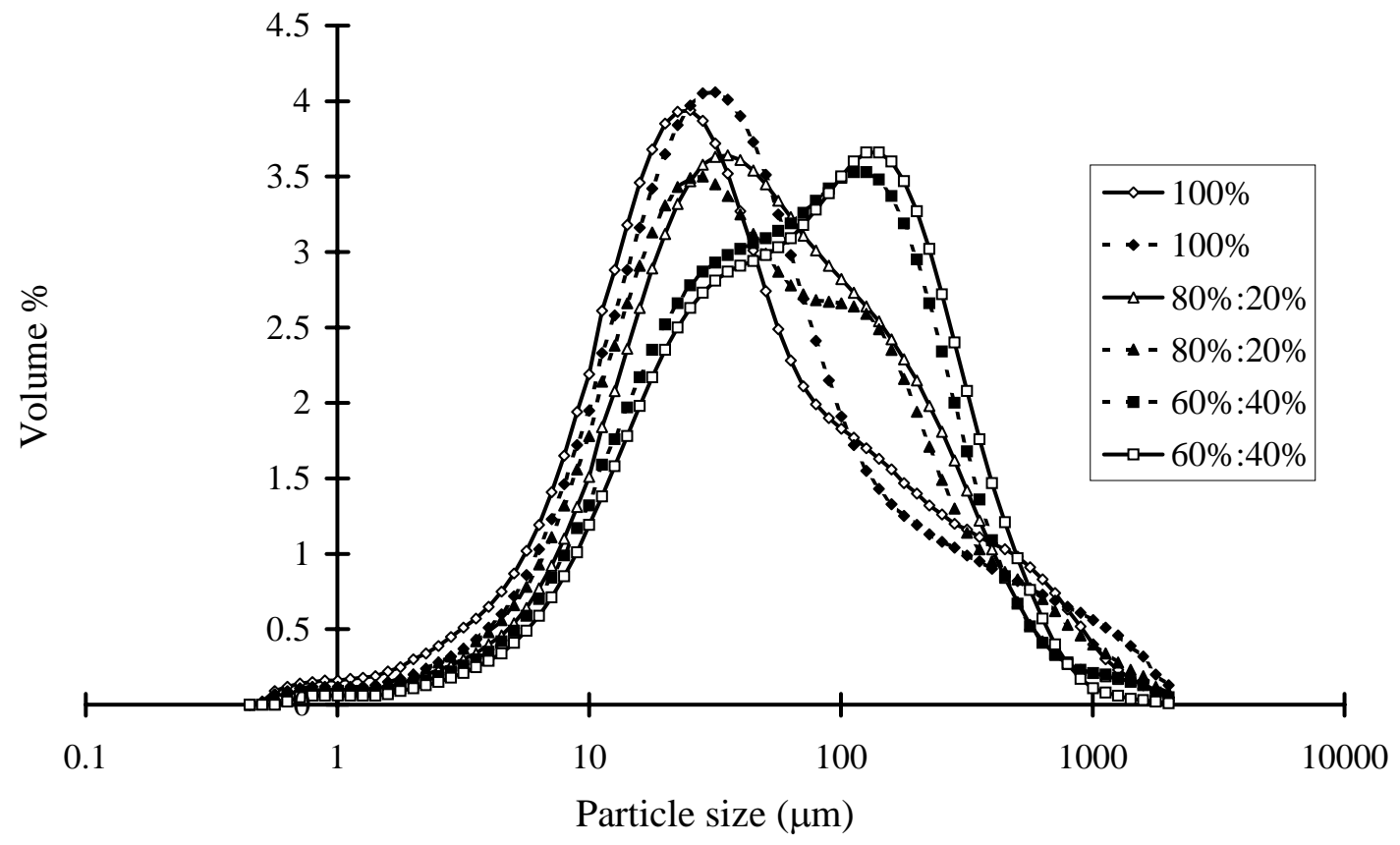

Figure 1. Digested sludge: average particle size distribution of waste sludge. 
Table 3. Digested sludge: $d(0.1), d(0.5)$ and $d(0.9)$ values of particle size distribution and sludge specific surface area.

\begin{tabular}{|l|c|c|c|c|}
\hline $\begin{array}{l}\text { Digester } \\
\left(1^{\mathrm{o}}: \mathrm{WAS}\right)^{*}\end{array}$ & \multicolumn{3}{|c|}{ Particle size distribution $(\mu \mathrm{m})$} & Specific surface area $\left(\mathrm{m}^{2} \mathrm{~g}^{-1}\right)$ \\
\hline & $\mathrm{d}(0.1)$ & $\mathrm{d}(0.5)$ & $\mathrm{d}(0.9)$ & 0.441 \\
\hline $100 \%$ & 6.9 & 30.5 & 292.2 & 0.378 \\
\hline $100 \%$ & 8.2 & 34.3 & 300.3 & 0.317 \\
\hline $80 \%: 20 \%$ & 9.8 & 44.8 & 245.3 & 0.350 \\
\hline $80 \%: 20 \%$ & 8.6 & 40.9 & 271.1 & 0.264 \\
\hline $60 \%: 40 \%$ & 10.9 & 61.1 & 257.9 & 0.231 \\
\hline $60 \%: 40 \%$ & 12.2 & 69.9 & 282.8 & \\
\hline
\end{tabular}

*primary to waste activated sludge ratio 